\title{
Numerical strength analysis of the roller for textile fabric handling
}

\author{
Numeryczna analiza wytrzymałościowa \\ wałka do transportu tkaniny tekstylnej
}

\section{WIES $\angle A W$ KOMAR \\ WOJCIECH MIACKOWSKI BARTOSZ MOCZULAK}

This paper presents the methodology of conducted numerical tests and experiments on the stress analysis in the roller for transporting textile fabrics, gained directly from the production line. The results of both analyses were compared and the tested object verified in terms of its operational safety. KEYWORDS: FEM numerical analysis, stress analysis, textile fabric

The numerical FEM analysis allows for an approximate but quick and costless estimation of Stress values in complex technical objects. However, the results of computer simulations are valid if verified, either with the results of analytical calculations or with the results of an experiment conducted on a real object. The essence

a)

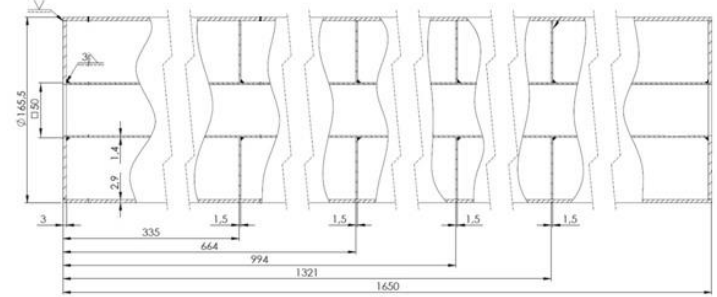

b)

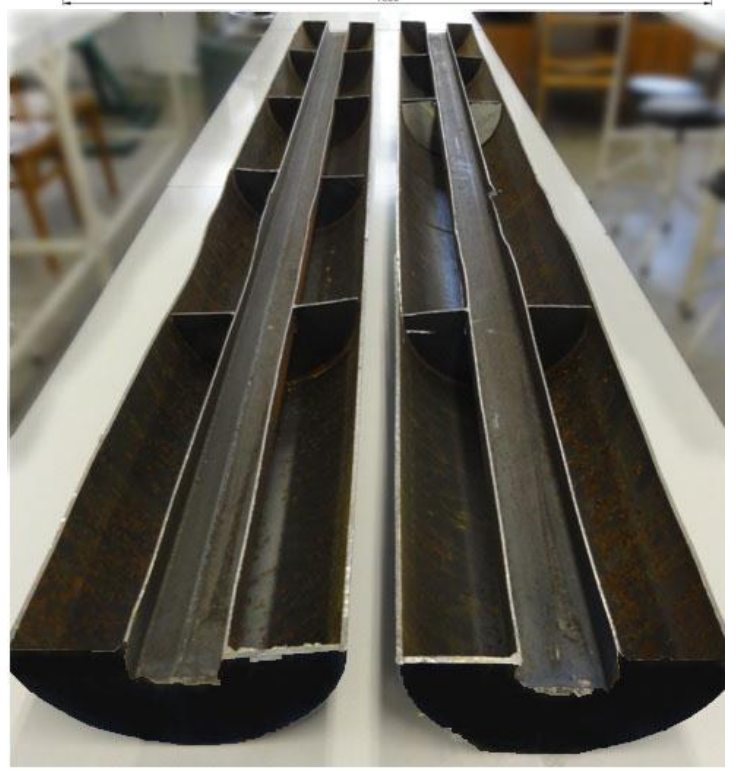

Fig. 1. Section of the roller for textile fabric transport: a) technical sketch used in FEM analysis, b) longitudinal section

* Dr inż. Wiesław Komar (komar@uwm.edu.pl ), dr inż. Wojciech Miąskowski (wojmek@uwm.edu.pl), mgr inż. Bartosz Moczulak, (bartosz.moczulak@uwm.edu.pl) - Wydział Nauk Technicznych Uniwersytetu Warmińsko-Mazurskiego
DOI: https://doi.org/10.17814/mechanik.2017.7.91

of the research was to verify the actual design of the roller used in the production process for interstate transportation of textile fabric for its safe use. The purpose of the study presented in this paper is the implementation of numerical strength calculations for this type of roller and their comparison with the results of analytical calculations based on actual data on the load and working conditions of the rollers.

\section{Subject of study}

The subject of the study is the design of a roller, on which the fabric is wound up in the production process, with specific geometry and under the given load conditions. Roller shape is a steel tube closed with welded circular profiles. Inside the pipe is a square tube, sealed continuously (metallurgical weld). The attachment of the circular outer tube and the inner tube to the external profiles is shown in fig. 1a and the longitudinal section of the roller is shown in fig. $1 \mathrm{~b}$.

In order to reinforce the structure, four profiles are inserted between the outer and inner tubes. Internal reinforcement profiles were only pinned to the square pipe and were not connected to the outer tube of the roller in any way.

After identifying and dimensioning the individual roller parts for each of them, material tests were carried out to determine the mechanical properties of the materials from which they were made. They were carried out on flat (strip) samples taken from individual rollers.

Static tension tests carried out within the framework of the study have allowed to determine:

- yield limit $R_{e}$,

- tensile strength of material $R_{m}$,

- relative elongation $A_{5}$,

- fatigue strength $Z_{g o}$.

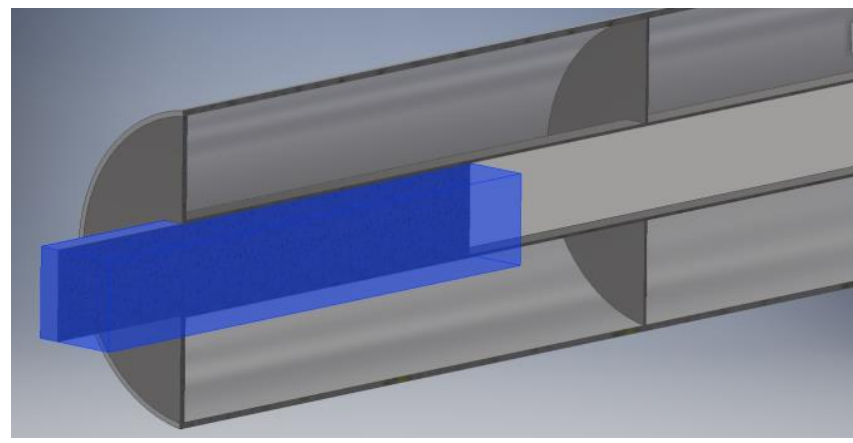

Fig. 2. Fixing shaft used in computer simulation 


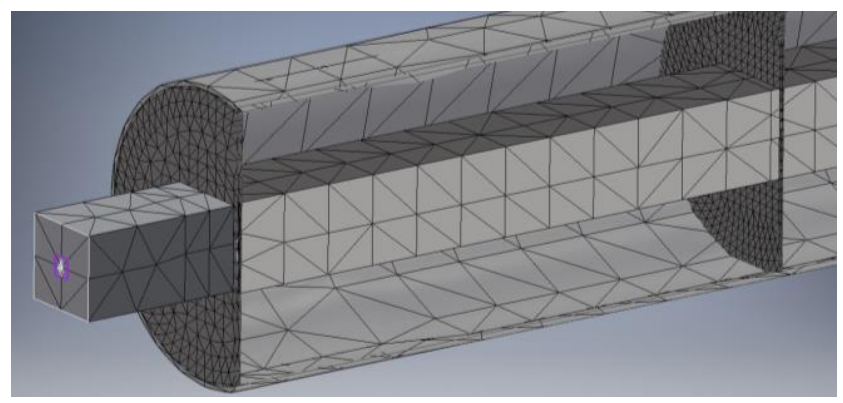

Fig. 3. Solid grid and stationary geometry on the shaft surface

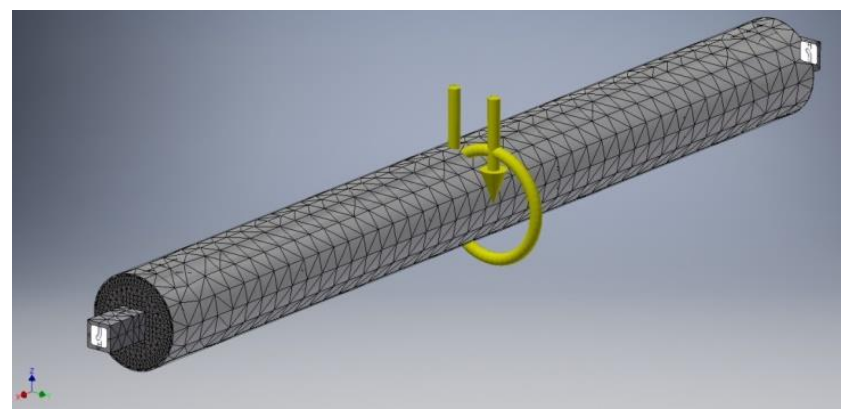

Fig. 4. Roller load in FEM analysis of outer pipe

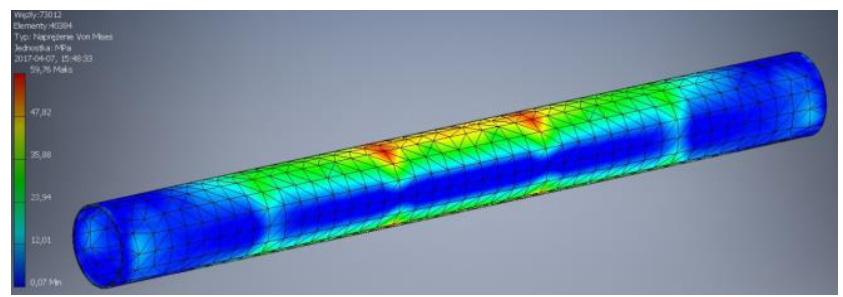

Fig. 5. Huber-Mises-Hencky reduced stress distribution in the outer tube of the textile fabric roller

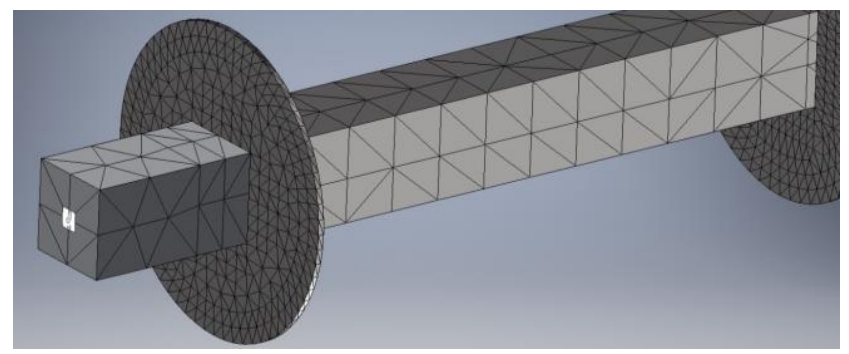

Fig. 6. Solid grid and fixed geometry on the surface of the fixing shaft

\section{Results and analysis of calculations}

In the strength calculation, the weight of the rollers is $1800 \mathrm{~kg}$, so the weight of $17660 \mathrm{~N}$ is assumed for the calculation. During winding, the shaft is mounted on two rigid, tightly fitting beams and supported all the length on two other rollers of the winder, one of which It acts as a driving unit (turning the shaft into a rotary motion) and the other - supporting the roller along with the fabric wound on it. The winding of the textile fabric wound on the shaft is transported by a crane to another production station. The external cylindrical pipe and the inner square tube are considered the most stressed components. The results of the analytical calculations are summarized in the Table.

Based on the value of safety factors, it is to be assumed that the most damage to the shaft element is the internal square pipe.
TABLE. Results of strength calculations of roller bearing elements

\begin{tabular}{|l|c|c|}
\hline \multicolumn{1}{|c|}{ Feature } & $\begin{array}{c}\text { External } \\
\text { pipe }\end{array}$ & $\begin{array}{c}\text { Internal } \\
\text { pipe }\end{array}$ \\
\hline $\begin{array}{l}\text { Maximum torque } M_{\text {smax }} \\
\text { Nmm }\end{array}$ & 206875 & 37575 \\
\hline $\begin{array}{l}\text { Maximum bending moment } \\
M_{\text {gmax }} \mathrm{Nmm}\end{array}$ & 3507187 & 869820 \\
\hline Tangential stress $\tau \mathrm{MPa}$ & 1,7 & 5,7 \\
\hline Normal stress $\sigma \mathrm{MPa}$ & 59,3 & 202,8 \\
\hline Reduced stress $\sigma \mathrm{MPa}$ & 59,4 & 203 \\
\hline Static safety factor $n_{\mathrm{s}}$ & 5,65 & 1,04 \\
\hline Fatigue safety factor $n_{\mathrm{z}}$ & 3,74 & 0,97 \\
\hline
\end{tabular}

FEM analysis. Geometric mapping and defining material parameters of construction elements were implemented in the numerical model. FEM analysis was performed in Autodesk Inventor. Simplified simulations used a solid grid and the actual load values given in the Table.

External pipe. The outer tube was analyzed in the context of deposition [1, 2]. All degrees of freedom were collected on one surface of the fixing brace (fig. 2 and fig. 3). The weight of transported fabrics was $17660 \mathrm{~N}$, torque $206875 \mathrm{Nm}$ and gravity $9810 \mathrm{~mm} / \mathrm{s}$ along $Z$ axis (fig. 4). It was decided to use automatically detected contacts between the components. 40384 finite elements (tetrahedrons) and 73012 nodes were used in computer simulation.

The highest stresses reduced by the Huber-MisesHencky hypothesis, determined in the outer pipe by numerical analysis, have a value of the order of $59 \mathrm{MPa}$ (fig. 5). This result is consistent with the results of the analytical calculations. Maximum reduced stresses occur in the middle part of the outer tube, i.e. in those areas of the shaft that are most susceptible to deformation caused mainly by the weight of the wound textile fabric.

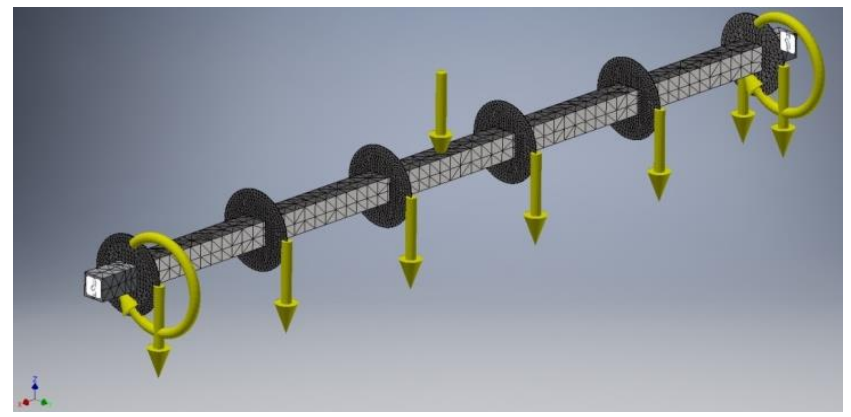

Fig. 7. Loads of elements in FEM analysis of inner pipe

Internal tube. The inner tube was also analyzed in the context of assembly, but with the exclusion of the outer tube (fig. 6).

The weight of the roller-loading fabric was applied to the cylindrical surfaces of the inner profiles and the torque effect was realized on the cylindrical surfaces of the extreme profiles (fig. 7). Values from Table have been adopted.

Numerical analysis of this part of the shaft also takes into account the influence of gravity. A solid grid was 
used to describe the object under investigation with 19713 tetrahedral elements, thus assigning 38743 nodes, and automatically detected contacts between the components of the structure [1]. A numerical analysis was performed for this formulation of the structural element and the load.

The stress distribution in this element takes the assumed form (fig. 8), but the value of the largest stresses is different from the stresses obtained from the analytical calculations. The highest stresses reduced by the Huber-Mises-Hencky hypothesis in the analytical calculations are $203 \mathrm{MPa}$ and $158 \mathrm{MPa}$ - in the FEM analysis.

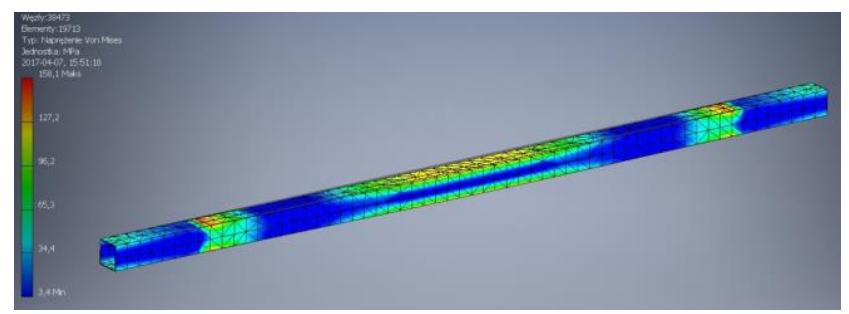

Fig. 8. Grid view and Huber-Mises-Hencky reduced stress distribution in the inner tube of the shaft

\section{Conclusions}

Results of the FEM analysis for the outer cylindrical pipe show compliance with the results of the analytical calculations. On the other hand, the results for the internal square tube show the difference in the maximum reduced stress, which may be due to simplification of the numerical model.

The results of the analysis show that the approach to modeling the load distribution and the corresponding stresses in the context of submission should be treated individually. Particular attention is required to the selection of boundary conditions, taken in numerical calculations.

When analyzing technical objects - even geometrically complex and subjected to relatively simple load conditions - experimental results verification is recommended.

\section{REFERENCES}

1. "Introduction to Using Inventor's Programming Interface". API Help, 2017.

2. Jaskulski A. „Autodesk Inventor Professional 2016PL/2016+/Fusion "360. Metodyka projektowania". Warszawa: Wydawnictwo Naukowe PWN, 2016 